\title{
Key Components of Tourism Destination Development
}

\author{
Janet Ratliff \\ Morehead State University \\ Michelle B. Kunz \\ Morehead State University
}

This paper examines variables that contribute to tourism revenues as reported by the state of Kentucky for a sample of 54 counties in Appalachian Kentucky. The study utilized five components of tourism, online promotional information, and reported tourism revenues to identify what variables contribute to regional tourism revenues. Regression analysis using factor scores found two factors influenced employment revenue and one factor influenced direct tourism revenue.

Keywords: SOAR initiative, destination tourism, destination branding, promotion and digital marketing

\section{INTRODUCTION}

\section{SOAR Initiative}

A Kentucky initiative known as Shaping Our Appalachian Region (SOAR) was established in the fall of 2013. Then Kentucky Governor, Steve Beshear, and Kentucky 5th District Congressman Hal Rogers realized the severity of the declining coal industry and its effects on the state, regional, and local economies. They also recognized the increasing economic struggles and challenges experienced by the entire state as a result. Believing that the region had reached a 'tipping point' and people were ready to begin an honest dialogue regarding the future, these leaders began a movement now known as the SOAR initiative.

SOAR is a network of our Appalachia that unites 54 counties worth of talent enabling us to shape our own future. Shaping Our Appalachian Region is a non-partisan economic development agency tasked to expand job creation, enhance regional opportunity, innovation, and identity, improve the quality of life, and support all those working to achieve these goals in Eastern Kentucky (SOAR, para 1).

The SOAR initiative includes seven goals, and the seventh goal in SOAR is to establish Kentucky's Appalachian region as a tourism destination ("Regional tourism development" n.d.). There are six tourism objectives: 1) leveraging existing assets; 2) regional branding and marketing; 3) increasing demand for local arts and crafts; 4) downtown redevelopment; 5) creating unique identities for communities; and 6) developing support for hospitality careers. Three of these goals are the foundation for this research. These three specific goals are: 
7.1. Support tourism projects that leverage existing assets to create attraction/destination based economic activity through private businesses such as theme parks, resorts, ATV Trails, etc.

7.2. Improve regional branding and marketing efforts to increase awareness and demand for recreational activities.

7.3. Build upon regional assets that create unique identities for communities (SOAR, blueprint).

\section{Purpose}

This research is grounded in the components (variables) of tourism that influence tourists' decisions to visit a location. The research is focused on tourism in Kentucky and specifically the SOAR initiative and respective fifty-four counties. The purpose of this study is to identify the current state of tourism offerings in these counties and determine which of these variables contribute to tourism revenues.

The discussion will provide a background of the Kentucky SOAR Initiative and a review of literature related to the economic impact of tourism, regional assets and economic development, destination tourism, and tourism/destination branding. It will also examine promotion and digital marketing geared toward tourists.

\section{BACKGROUND}

\section{Economic Impact of Tourism}

According to Turner and Freirmuth (2017), in 2016, travel and tourism contributed \$7.6 trillion USD (10.2\% of global GDP) and 292 million jobs (the equivalent of 1 in 10 jobs) to the global economy; this sector accounted for almost $30 \%$ of total global service exports and approximately $6.6 \%$ of total global exports. Turner and Freirmuth (2017) further report that these figures are expected to continue to rise over the next 10 years. In essence, they state: "Travel \& Tourism creates jobs, drives exports, and generates prosperity across the world" (p. iii). These authors reported growth in the travel and tourism sector has increasingly outpaced that of the global economy $(2.5 \%)$, and tourism growth is increasingly stronger than the growth recorded in other sectors.

Economic effects of the travel and tourism sector are anticipated to continue to increase for both direct and indirect contributions of the travel and tourism sector. Direct contributions include economic activity from hotels, restaurants, leisure industries, airlines, among other items. Indirect contributions include economic activity from the GDP and jobs supported by the spending of those who are directly or indirectly employed by the travel and tourism industry as a whole. In addition, it is important that nations recognize the significance placed on this sector as an engine of economic development. Investment and development must continue to foster open and sustainable practices to provide a means to share cultures, create peace and build on-going mutual understanding between and among varying nations to achieve tourism potential (Turner and Freirmuth, 2017).

\section{REVIEW OF LITERATURE}

\section{Regional Assets and Economic Development}

This literature discussion relates to SOAR's tourism objectives focused on regional assets and the overall SOAR initiative goal of economic development. Research by Aksoz and Arikan (2008) noted some of the necessities needed for tourism development within a region. The region should contain an infrastructure that is supportive of tourism. Therefore, there is an importance placed on utilities, roads, business services, and other social services that support both tourists' needs and tourism businesses. The region visited should be larger than just one community or a single attraction, and it should be able to develop into an area to support multiple attractions to draw tourists. Their research continues to explain that the region should also be capable of supporting tourism planning and marketing initiatives that cultivate a continued effort for development into the future.

Assaker, Vinzi, and O'Connor (2011) investigated the relationship between the economy, society, natural and infrastructural environments of a tourism destination, along with the demand for that 
destination by tourists. The results indicated that the more developed the society, the more tourism activities were supported. The authors did not find a significant relationship between the economy and tourism, but did determine the infrastructure and supporting environment have a significant impact on the experience tourists had. Additional research by Goffi (2013) resulted in similar findings when investigating the competitiveness of a tourism destination. The study identified thirteen factors that affected competitiveness, including the general infrastructure, quality of the natural resources, and local economic development. Goffi's research also identified physical components of the location such as events, activities, accommodations, food services, historic and artistic attractions, as well as the management and marketing strategy of the destination impacted tourism.

\section{Destination Tourism}

The first SOAR objective, leveraging existing assets to create attraction/destination based economic activity, leads to the following discussion of destination tourism. Five components of tourism that impact any location/destination were identified by Aksoz and Arikan (2008). The first of these was identified as attractions, as it might seem obvious there has to be something that would draw tourists to a location or destination. The researchers noted there are a variety of items that could fall into attractions, including natural environmental resources such as lakes, waterfalls, or mountains. Attractions could also include historic venues such as buildings, monuments, or churches. Man-made venues such as waterparks or theme parks can also build demand for a destination. Elements of the geographic infrastructure such as roads, highways, mass transit, airport and rail systems provide tourists the ability to physically travel to the destination. Aksoz and Arikan termed this component of tourism accessibility. The third component of tourism the researchers identified as activities, encompasses a wide variety of items that enhance the tourist's experience at the destination. These varying activities may include nature/outdoors such as camping, hiking, and fishing. It also may include activities such as museum visits, sporting events, music, or other forms of entertainment. By default, a tourism destination that generates demand will require accommodations for those who come to visit the destination. The researchers noted that accommodations, the fourth component may be required not only at or near the specific location, but also as tourists travel to and from a specific destination. The fifth and final tourism component identified by Aksoz and Arikan was amenities. Amenities include most importantly food/restaurants at a minimum, but may also include shopping, and informational sources on tourist information or other tourism-friendly offerings.

Research by Omerzel (2011) suggests that a tourism destination and tourism demand are inter-related. More specifically, the destination is the reason for travelling to a location, but the attractions of the location (destination) produce/develop tourism demand. A tourism destination is perceived by the tourist(s) as an overall "product" consisting of the natural environmental resources, the culture, and artistic offerings. The destination is developed as a mixture of these attractions and the services offered. When examining the potential for Slovenia to be developed as a tourism destination, Omerzel concluded these factors influenced the demand: inherited and created resources, management, situational conditions and supporting factors.

\section{Destination Branding and Marketing}

The following discussion will review literature related to the second SOAR objective: improve regional branding and marketing efforts to increase awareness and demand. One must recognize there is a difference between branding a product, where consistency and stability are essential elements of brand equity and branding a place (Gartner, 2014). A place or destination is a continually evolving and changing entity. The residents, environment, and overall entities of a place change. Thus, Gartner cautions there is a risk in branding a destination, since by its inherent characteristics, it will change and transform. Research by Kemp, Childers and Williams (2012) regarding promotional campaigns found clever messages can be successfully used to distinguish brand images for locations (destinations). Some readily identifiable slogans such as the following have been used successfully over time and endured for many years: What happens in Vegas, Stays in Vegas; Unbridled Spirit for Kentucky; Wet, Wild, Wonderful West Virginia. 
Recent research by Dioko (2016) noted that tourism promotional efforts have moved away from a general perspective and now focus on destination branding of places. While interest in destination marketing began almost forty years ago, a little more than a decade ago, the literature and interest moved to marketing and promotion of cities and places, with places remaining strong. Dioko concludes that these efforts have melded into destination branding. However, Foroudi, et al., (2016) conducted research trying to link the concepts of place branding, place image, and place reputation. They found place branding puts a focus on cities, specifically attractions and location image. They believe destination branding is a spinoff of place branding, and directed to tourism. Their research determined identification of what a place has to offer is based in three primary areas: natural and cultural resources, differentiation from other competing destinations, and a commitment by the government to support tourism. Additionally, research by de San Eugenio Vela, Nogué, and Govers (2017) emphasized that failure to coordinate between institutions and organizations can negatively impact destination branding, and successful destination branding requires coordinated efforts among all entities.

\section{Unique Identities}

The fifth objective of the SOAR objective is to create unique identities for communities based upon regional assets. Research by Kesic and Pavlic (2011) determined the image of a tourism destination has to be grounded in a true identity. Developing the image and identity of a destination are critical elements of marketing strategy and tactics. The authors conclude effective destination tourism is dependent upon a unique combination of marketing strategies. This leads to a discussion of promotion and marketing efforts.

\section{Promotion and Digital Marketing}

Information communication technology (ICT) is one of the driving forces within the tourism industry. Currently, more than one-half of the entire world population uses the Internet (Internet World Stats, 2018). Led by the fact that tourism marketing systems are generally found at the forefront of multimedia and virtual-reality application, it certainly makes sense that the World Wide Web is changing the production, distribution, and consumption of tourism products (Sevrani \& Elmazi, 2013). In fact, traditional marketing and/or promotion channels such as cable broadcast television or advertising in magazines have been replaced over time with digital marketing (Martin, 2015). Digital marketing is defined by George Schildge with Matrix Marketing Group in Martin (2015) as "creating a more connected customer experience via marketing that makes use of every electronic device imaginable to engage stakeholders" (p.18). As such, the researchers also reported 91\% of industry professionals surveyed believed digital marketing is becoming an important or very important part of their respective marketing efforts overall. By 2019, it is estimated spending on digital marketing is expected to outpace combined marketing budgets for both cable and broadcast television advertising (Martin, 2015).

Parlov, Perkov, and Sicaja (2016) analyzed marketing activities and communication strategies of European countries, and specifically Croatia, to provide a model for development of Croatian tourism into a global brand using digital marketing. Essentially, Croatia needs to introduce new technologies for marketing purposes. Countries that are on top of tourism take advantage by exemplifying the following strategies: 1) use all possible platforms; 2) develop overall identity and destination branding; 3) create and communicate a clear message and identity; use web sites that are more accessible, interactive, and easier to use; 4) utilize search engine optimization; 5) subscribe to highly personalized email marketing; 6) use mobile e-marketing; and 7) manage social networks. This research presented new trends in tourism destination branding by using digital marketing that illustrated the importance and value of digital marketing to the worldwide tourism industry. Research by Cheuk, et al., (2017) further discussed the importance of ICT in rural tourism and provided a baseline study on rural community attitudes towards the usage of digital marketing in tourism. It is thought that effective marketing efforts, such as those provided through digital means could be extremely helpful in providing recognition to rural areas in the tourism marketplace. Since many counties and communities within Kentucky are considered rural, specifically those included in the SOAR initiative, these considerations become vital to those counties in 
Kentucky as they move into the tourism marketplace and hope to establish a presence there. Currently, in the counties studied, marketing efforts do not go much beyond simple websites.

\section{METHODOLOGY}

Based upon this literature discussion, the purpose of this study is to determine if variables identified by previous research influence tourism revenues and thus provide further insights to support SOAR initiatives and activities. The framework used is based upon Aksoz and Arikan (2008) five components of tourism.

The variables for this study, based upon Aksoz and Arikan (2008) tourism components, were operationalized using the following descriptions. Attractions were defined as anything that drew tourists to a location such as man-made venues (parks, festivals, tournaments), natural/environmental features (lakes, trails, waterfalls) and historical sites. Activities are available on a continuing basis for both local residents and tourists. These were defined as: golfing, camping, hiking, fishing, boating, among other opportunities. We identified the facilities that would provide these activities. Accessibility is the infrastructure that would allow tourists to access the area for tourist activity. This was operationalized as highways (local/state) and interstates. Accommodations would provide a place for tourists to stay for any duration at a particular location, and included: hotels, motels, bed and breakfasts, Airbnb, and campgrounds. Amenities were defined as restaurants and food providers.

The researchers used websites and online resources from chambers of commerce, Kentucky State Tourism, and county governments. Additional information was collected using U.S. Census data on population, environmental characteristics such as land and water mass, and the availability of alcohol sales. This last item was included by the researchers because economic development discussions frequently address this topic.

Revenue measures were available from the Kentucky Tourism website ("Regional Tourism Development", 2018). Direct tourism expenditures or revenues are classified as direct expenditures by consumers. Employment represents the wages generated from tourism-related jobs. These two measures comprise the dependent variables (employment and direct tourism expenditures) examined in this study.

\section{Data Collection}

Data were collected in the spring of 2018, and the sample consisted of the fifty-four counties in Kentucky identified in the SOAR initiative as part of Appalachia. The researchers began data collection by using the Kentucky State Tourism website links to local county tourism websites. The initial phase of data collection consisted of a frequency count for each of the five tourism components present on the respective county website. Additional data counts were collected using U.S. Census data for population, land and water mass, and alcohol sales. Accessibility was determined by examination of road maps to identify highways, parkways and interstates of each county. Yelp and Google Search were used to identify and verify the accommodations and amenities. The number of attractions for each individual county ranged from 0 to 25 ; accessibility ranged from 0 to 9 ; activities ranged again from 0 to 25 ; accommodations ranged from 0 to 41 ; amenities ranged from 0 to 135 .

Physical characteristic results of the raw data collection revealed wide ranging counts for many variables. Land mass ranged in square miles from forty-four to 787. Water mass ranged from .20 to 937 square miles. Population density per square mile ranged from twenty-two to 310 . Twenty-two counties have no alcohol sales. Nineteen counties allowed alcohol sales, and thirteen counties are classified as moist, allowing sales in specific cities not county-wide.

While collecting data, the researchers became cognizant of the differences in the quality and quantity of information provided in the county tourism websites. These online sources are a means of promotion for the counties studied. As a result, the researchers felt that it was important to add another variable, the promotional component of online platform, in this case the webpage. The new component of tourism, labeled by the researchers as awareness could be considered the sixth A. Awareness, the sixth A, comprises the quality and attractiveness of individual websites connected to the state tourism website. 
This qualitative evaluation of the website considered the quality of graphic images, use of video and quality of such video. It was scored on a scale of 0 to 3 by each researcher independently, and then jointly a consensus rating was determined.

The researchers measured the original five tourism components (5A's) by providing a count of the individual items for each variable. The sixth component of tourism, awareness, included the following data: 1) presence or absence of a local tourism website; 2) website quality; 3) the number of information categories on the website; and 4) existence or not of a unique slogan or tagline. Only thirty-seven of the fifty-four counties studied had tourism website. Twelve of these counties provided links to one or more additional web resources. Seventeen websites were rated by the researchers as a 3 . Websites were analyzed to determine the number of categories used to identify tourism-related resources in the county. The number of categories ranged from one to twelve. A slogan was present on twenty of the websites.

\section{RESULTS}

Data analysis began by conducting a factor analysis of all sixteen variables using the principal component method. The factor analysis identified five factors from the sixteen variables. Factor 1 was comprised of attractions, activities and amenities (three of the five A's); Factor 2 included all components of the website (additional site links, number of information categories, website quality, and slogan). This factor would comprise information marketing (i.e. building awareness). Factor 3 included alcohol and accessibility; Factor 4 included accommodations, population density and water area; Factor 5 included population and land area.

Following the factor analysis, stepwise regression analysis was conducted using factor scores (independent variables) and 2017 employment revenue (dependent variable). This analysis identified two factors that were significant. Factor 1 ( 3 A's) results were statistically significant ( $p=.002)$, with the F ratio of 11.024 and an adjusted $\mathrm{R}^{2}=.159$. Factor 2 (awareness) results were statistically significant $(\mathrm{p}=.000)$, with the $\mathrm{F}$ ratio of 9.993 and adjusted $\mathrm{R}^{2}=.253$. This means that three of Aksoz and Arikan's 5 A's explain $15.9 \%$ of employment expenditures and the $6^{\text {th }}$ A, awareness, explains $25 \%$ of employment revenues. See Table 1.

TABLE 1

STEPWISE REGRESSION ANALYSIS FOR 2017 EMPLOYMENT

\begin{tabular}{|l|l|l|l|l|l|l|l|l|}
\hline $\begin{array}{l}\text { Dependent } \\
\text { Variable }\end{array}$ & Variables & $\beta$ & $t$ & $p$ & $\mathrm{R}^{2}$ & Adj $\mathrm{R}^{2}$ & $F$ & Sig. \\
\hline Employment & $\begin{array}{l}\text { Attractions, } \\
\text { Activities \& } \\
\text { Amenities } \\
\text { (Factor 1) }\end{array}$ & 333.120 & 3.524 & 0.01 & .175 & .159 & 11.024 & .002 \\
\hline Employment & $\begin{array}{l}\text { Awareness } \\
\text { (Factor 2, website) }\end{array}$ & -260.088 & -2.751 & .008 & .282 & .253 & 9.993 & .000 \\
\hline
\end{tabular}

A second stepwise regression analysis was conducted using factor scores (independent variables) and 2017 direct tourism revenue (dependent variable). Factor 2 (the $6^{\text {th }} \mathrm{A}$, awareness) was the only statistically significant factor $(\mathrm{p}=.048)$, with the $\mathrm{F}$ ratio of 4.095 and an adjusted $\mathrm{R}^{2}=.055$. While these results indicate awareness explains only $5.5 \%$ of direct tourism revenue, it is the only factor that was found to be statistically significant. See Table 2. 
TABLE 2

STEPWISE REGRESSION ANALYSIS FOR 2017 DIRECT EXPENSES

\begin{tabular}{|l|l|l|l|l|l|l|l|l|}
\hline $\begin{array}{l}\text { Dependent } \\
\text { Variable }\end{array}$ & Variables & $\beta$ & $t$ & $p$ & $\mathrm{R}^{2}$ & $\begin{array}{l}\text { Adj } \\
\mathrm{R}^{2}\end{array}$ & $F$ & Sig. \\
\hline $\begin{array}{l}\text { Direct } \\
\text { Expenses }\end{array}$ & $\begin{array}{l}\text { Awareness } \\
\text { (Factor 2, } \\
\text { website) }\end{array}$ & -8866433.432 & -2.024 & .048 & .073 & .055 & 4.095 & .048 \\
\hline
\end{tabular}

To validate the model, regression analysis was repeated using both forward and backward regression analysis using the same factor scores as the independent variables and the same dependent variable (first 2017 employment and second 2017 direct revenue). All were consistent with the results of the stepwise regression analysis, producing the same results.

\section{DISCUSSION}

Three of Aksoz and Arikan's (2008) tourism components, attractions, activities and amenities as well as the $6^{\text {th }} \mathrm{A}$, awareness, contribute to employment revenue. None of the other variables identified including accommodations, accessibility, alcohol sales, the geographic characteristics and population were found to be contributors to employment revenue. This would indicate that things to do and enjoy along with gastronomic experiences are main contributors to employment revenue. These three variables all require human labor support. The other contributing factor is the marketing/promotion of the local county offerings (i.e. website).

Even more interesting is that only awareness impacted direct tourism revenue (i.e. direct revenue for tourism activities). The website and the information found on that website impacts the marketing and promotion that gets tourists to the county and thus generates tourism revenue.

\section{CONCLUSION}

This research found that awareness, marketing and promotion, of a destination is what influences both the employment of an area as well as the direct revenue of an area. This becomes a key component of accomplishing SOAR objectives and thus warrants further research. Digital marketing is the integration of technology into daily activities using social media and other forms of information communication technology. In the field of tourism, the Internet and more specifically social media, provide the means by which tourists seek information. Social media is considered to have a high level of credibility because it is an induced and organic source where the information is generated by users that have more control on content generation and utilization. According to the findings of $\mathrm{Oz}$ (2015), social media use is widespread in consumers' daily lives including travel related purposes. Additionally, consumers use social media more in their pre-travel research than at any other time. These findings illustrate the importance of social media to the tourist from a tourism marketing perspective.

Research by Pabel and Prideaux (2016) noted the importance of understanding the problems small destinations face in raising their online presence including consumer use of social media in addition to the broader trends of social media consumption. They also explained that a detailed understanding of what tourists desire in locations and activities and the ability to create personalized activity schedules would become increasingly important over time. The development of a social media strategy is required to achieve these outcomes. This is exactly the case in Kentucky, where all but a few areas within the state are essentially small destinations. Transforming a state into a very proactive and smart tourism provider will require well-designed strategies, and time for counties, communities, and regions to evolve. 


\section{LIMITATIONS}

Preconceived biases on the part of the researchers directed the collection of data regarding land and water mass, sales of alcohol, and travel accessibility. However, the results indicate that the variables do not significantly impact expenditures and revenues. Awareness (the $6^{\text {th }}$ A) only examined the websites that were linked from the Kentucky State tourism website. No data was collected in the study regarding the use of social media and other communication technology for the local websites. Examination of slogans/taglines could relate to the branding objectives of the SOAR initiative. Additionally, data collection for this study examined data collected only from the 54 counties included in the SOAR initiative.

\section{FUTURE RESEARCH}

In this study, research indicates that digital marketing (i.e. building awareness) is a key component of providing the information tourists need to identify destinations they wish to visit. This study demonstrates the impact marketing has on tourism revenue. Since awareness/marketing was the only significant component/variable for both the employment and tourism revenue, it appears as though the next step in this research should focus on social media and digital marketing that were not addressed in this study and that could provide a catalyst to smart tourism for the state of Kentucky. The Kentucky Tourism website divides the state into regions, based upon topography and tourism-related activities. Thus, the next phase of research should collect data regarding tourism promotional websites across the state and then compare results for each of the identified regions. Such a study could confirm the results of the current study.

\section{REFERENCES}

Aksoz, E. O., \& Arikan, I. (2008, June 11-14). An Approach for Heritage Tourism Destination Development. Paper presented at An Enterprise Odyssey, Intenational Conference, Zagreb, Croatia.

Assaker, G., Vinzi, V., \& O'Connor, P. (2011). Modeling a causality network fortourism development: an empirical analysis. Journal of Modelling in Management, 6(3), 258-278.

Cheuk, S., Atang, A., Lo, M., \& Ramayah, T. (2017). Community Perceptions on the Usage of Digital Marketing for Homestays: The Case of Ba'Kelalan, Malaysia. International Journal of Business and Society, 18(4), 775-782.

de San Eugenio Vela, J., Nogué, J., \& Govers, R. (2017). Visual Landscape as a Key Element of Place Branding. Journal of Place Management and Development, 10(1), 23-44.

Dioko, L. A. N. (2016). Progress and trends in destination branding and marketing - a brief and broad review. International Journal of Culture, Tourism and Hospitality Research, 10(1), 5-13.

Foroudi, P., Gupta, S., Kitchen, P., Foroudi, M. M., \& Nguyen, B. (2016). A framework of place branding, place image, and place reputation. Qualitative Market Research, 19(2), 241-264.

Gartner, W. C. (2014). Brand equity in a tourism destination. Place Branding and Public Diplomacy, $10(2), 108-116$.

Goffi, G. (2013). A model of tourism destination competitiveness: The case of the Italian destinations of excellence. Turismo y Sociedad, 14.

Internet World Stats: Useage and Population Statistics. (2018). Retrieved June 27, 2018, from https://www.internetworldstats.com/stats.htm

Kemp, E., Childers, C. Y., \& Williams, K. H. (2012). Place branding: creating self-brand connections and brand advocacy. The Journal of Product and Brand Management, 21(7), 508-515.

Kesic, T., \& Pavlic, I. (2011). Tourism destination image formation - the case of Dubrovnik, Croatia. Tržište/Market, 23, 7-25.

Konecnik, M., \& Go, F. (2008). Tourism destination brand identity: The case of Slovenia. Journal of Brand Management, 15(3), 177. 
Martin, E. J. (2015). The state of digital marketing. Retrieved June 27, 2018, from Econtentmag.com Martin, E. J. (2017). The state of social media. Retrieved June 27, 2018, from Econtentmag.com Mikulic, J., Miliäevic, K., \& Kresic, D. (2016). The relationship between brand strength and tourism intensity: empirical evidence from the EU capital cities. International Journal of Culture, Tourism and Hospitality Research, 10(1), 14-23.

Omerzel, D. G. (2011). Stakeholders' understanding of factors influencing tourism demand conditions: The case of Slovenia. Tourism and Hospitality Management, 17(1), 1-17.

Oz, M. (2015). Social media utilization of tourists for travel-related purposes. International Journal of Contemporary Hospitality Management, 27(5), 1003-1023.

Pabel, A., \& Prideaux, B. (2016). Social media use in pre-trip planning by tourists visiting a small regional leisure destination. Journal of Vacation Marketing, 22(4), 335-348.

Parlov, N., Perkov, D., \& Sicaja, Z. (2016). New trends in tourism destination branding by means of digital marketing. Acta Economica Et Turistica, 2(2), 101-236.

Regional tourism development. (n.d.) Retrieved February 6, 2018, from http://www.soarky.org/blueprint/tourism

Sevrani, K., \& Elmazi, L. (2013). ICT and the changing landscape of touirsm distribution- a new dimension of tourism in the global conditions. Revista de Turism, (2), 22-29.

SOAR. (n.d.). Retrieved June 14, 2018, from http://www.soar-ky.org

SOAR about us. (n.d.). Retrieved June 14, 2018, from http://www.soar-ky.org/about-us

SOAR blueprint. (n.d.) Retrieved February 6, 2018, from http://www.soar-ky.org/blueprint

SOAR history. (n.d.). Retrieved March 12, 2018, from http://www.soar-ky.org/about-us

Turner, R., \& Freirmuth, E. (2017). The economic impact of travel and tourism London: World Travel \& Tourism Council. Retrieved March 15, 2018, from: https://www.wttc.org//media/files/reports/economic-impact-research/regions-2017/americas2017.pdf 